\title{
Modeling and Simulation of a Tubular Linear Switched Reluctance Actuator
}

\author{
Fawwaz Nadzmy, Mariam Md Ghazaly
}

\begin{abstract}
In this paper, 2-D finite element analysis and MATLAB/Simulink software are used to model and simulate the proposed tubular linear switched reluctance actuator. The analysis of the actuator by finite element is essential for determining the magnetization characteristics. The obtained data from the analysis is useful for testing and verifying the machine operation performance and behavior. According to the analysis, when a step current signal of $3 A$ was applied to the actuator, oscillation occurred at beginning of the motion with maximum overshooting of $2 \mathrm{~mm}$ and settling time of $0.15 \mathrm{~s}$. Besides, the force analysis showed there was nonlinear force behavior between $3.5 \mathrm{~N}$ and $2 \mathrm{~N}$ observed from the actuator motion. The saturation and nonlinear magnetization curve of materials causes the nonlinearity characteristics of thrust force and magnetic flux which affect the performance of the actuator. The determination of the characteristics and performance is crucial for the proposed actuator to realize a precision positioning system in the future.
\end{abstract}

Keywords: Finite element analysis, modeling, tubular linear switched reluctance actuator.

\section{INTRODUCTION}

In semiconductor industry, motion control and precision positioning play an essential role in production such as in die bond and wire bond process. Most processes require linear actuators in their operation. Recently, there are several types of linear actuator which commercially used such as pneumatic and hydraulic. As kind of linear actuator, linear switched reluctance actuator (LSRA) becomes an attractive alternative technology to other linear actuators owing to a simple, low production cost, no intermediary mechanical gear, no permanent magnet and durable structure. It has been proposed for application such as precision motion control [1]-[7]. Typical LSRA can divided into three distinct topologies, single-sided planar, doubleside planar and tubular type [8]. In addition, depending on the adjacent magnetic flux route, the actuator structure can be configured into longitudinal flux or transverse flux. For longitudinal flux, the flux line and actuator movement is in parallel while in transverse, the flux line is perpendicular with actuator movement. According to prior LSRA doublesided [9]-[11], single sided [12] and tubular [13], [14] modeling analysis, the switched reluctance type of machine has extremely nonlinear characteristics. Therefore, designing and developing the performance of the actuator is become more challenging. Examination of actuator characteristics is essential for predicting the steady state and the dynamic performance, i.e. to express flux linkage and

Revised Manuscript Received on September 14, 2019.

Fawwaz Nadzmy, Faculty of Electrical Engineering, Universiti Teknikal Malaysia Melaka, Hang Tuah Jaya, 76100 Durian Tunggal, Melaka, Malaysia.

Mariam Md Ghazaly, Center for Robotic and Industrial Automation (CeRIA), Faculty of Electrical Engineering, Universiti Teknikal Malaysia Melaka, Hang Tuah Jaya, 76100 Durian Tunggal, Melaka, Malaysia. )Email: mariam@utem.edu.my). thrust force as a function of excitation current and mover linear position.

This paper is devoted to modelling and simulation of proposed a longitudinal tubular linear switched reluctance actuator (T-LSRA) by using 2-D finite element analysis (FEA) and MATLAB/Simulink software. The description of the designed T-LSRA is presented in section II. The design is characterized by compact stator structure and easily replaceable mover since it is independent with the stator. The structure and dimensions of T-LSRA design had been optimized in [15]. In section III, the finite element analysis is elaborated. The flux and force characteristics calculated by finite element method are discussed in this section. Section IV elaborates the dynamic mathematical model of the machine. In section V, the MATLAB/Simulink model is constructed based on the electromagnetic curve. In this section, the simulation results are discussed. Finally, section VI presents the conclusions of this paper.

\section{DESIGN STRUCTURE \& METHODOLOGY}

The designed longitudinal T-LSRA is three phases' actuator which consists of twelve stators and a mover that made from the carbon steel. Therefore, there are 24 coils winding and twelve stator slots are included in the design. To produce a continuous motion, three phases of current excitation are implemented. Therefore, for each phase, eight coils are connected in series. The structure of linear switched reluctance motor with 12:8 stator-to-mover pole pairs is shown in Fig. 1.

In general, the driving current of T-LSRA is applied to the phase coils sequentially for performing a linear motion of the mover. The thrust force generates high attraction from the mover tooth near to the active stator pole. When the mover tooth moves near to the centre of the pole, the active coils are switched to generate a continuous motion up to $15 \mathrm{~mm}$. Table- I and Table- II show the current excitation sequence for forward and reverse motion. For forward motion, the current excitation sequence is A-C-B while in backward motion is A-B-C. The compact size of the proposed actuator is around $120 \mathrm{~mm} \times 57 \mathrm{~mm}$. Fig. 2 shows actual dimensions of the T-LSRA which provides a full view of the actuator structure. The mechanical and electrical parameters of the actuator are summarized in Table- III. 


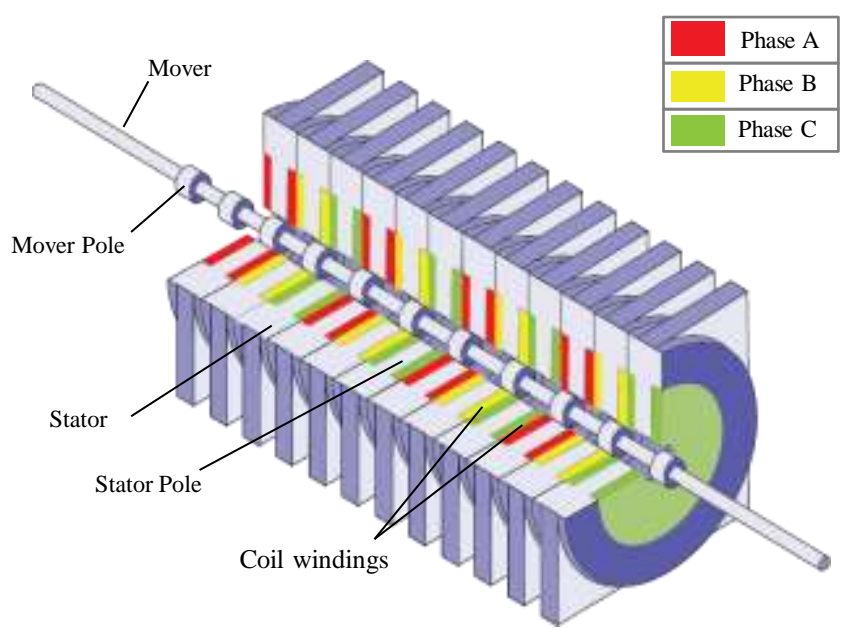

Fig. 1.Design structure of proposed tubular linear switched reluctance actuator.

Table- I: Current excitation sequence for forward motion

\begin{tabular}{|l|l|}
\hline Positions & $\begin{array}{l}\text { Phas } \\
\text { e }\end{array}$ \\
\hline $0 \mathrm{~mm}-5.0 \mathrm{~mm}$ & A \\
\hline $\begin{array}{l}5.0 \mathrm{~mm}-10.0 \\
\mathrm{~mm}\end{array}$ & C \\
\hline $\begin{array}{l}10.0 \mathrm{~mm}- \\
15.0 \mathrm{~mm}\end{array}$ & B \\
\hline
\end{tabular}

Table- II: Current excitation sequence for backward motion

\begin{tabular}{|l|l|}
\hline Positions & $\begin{array}{l}\text { Phas } \\
\text { e }\end{array}$ \\
\hline $0 \mathrm{~mm} 5.0 \mathrm{~mm}$ & A \\
\hline $\begin{array}{l}5.0 \mathrm{~mm}-10.0 \\
\mathrm{~mm}\end{array}$ & B \\
\hline $\begin{array}{l}10.0 \mathrm{~mm}- \\
15.0 \mathrm{~mm}\end{array}$ & C \\
\hline
\end{tabular}

Table- III: Parameters of designed actuator

\begin{tabular}{|l|l|l|}
\hline $\begin{array}{l}\text { Symbo } \\
\mathbf{l}\end{array}$ & Parameter & Value \\
\hline $\mathrm{M}$ & Actuator Materials & $\begin{array}{l}\text { AISI } \\
1045\end{array}$ \\
\hline$n$ & $\begin{array}{l}\text { Number of winding } \\
\text { turns }\end{array}$ & 60 \\
\hline$P$ & Number of phases & 3 \\
\hline$N$ & $\begin{array}{l}\text { Number of coil per } \\
\text { phase }\end{array}$ & 8 \\
\hline$D_{1}$ & Stator outer diameter & $57 \mathrm{~mm}$ \\
\hline$D_{2}$ & Stator inner diameter & $37 \mathrm{~mm}$ \\
\hline $\mathrm{T}$ & $\begin{array}{l}\text { Stator } \\
\text { thickness }\end{array}$ & $10 \mathrm{~mm}$ \\
\hline$h_{1}$ & Stator tooth width & $5 \mathrm{~mm}$ \\
\hline$h_{2}$ & Stator slot width & $2.5 \mathrm{~mm}$ \\
\hline$h_{5}$ & Stator tooth height & $14 \mathrm{~mm}$ \\
\hline$L_{2}$ & Stator length & $120 \mathrm{~mm}$ \\
\hline$d_{l}$ & $\begin{array}{l}\text { Mover } \\
\text { diameter }\end{array}$ & $8 \mathrm{~mm}$ \\
\hline$h_{3}$ & Mover tooth height & $1.5 \mathrm{~mm}$ \\
\hline$h_{4}$ & Mover tooth width & $5 \mathrm{~mm}$ \\
\hline$p$ & Mover tooth pitch & $10 \mathrm{~mm}$ \\
\hline$L_{l}$ & Mover length & $420 \mathrm{~mm}$ \\
\hline$g$ & Air gap thickness & $0.5 \mathrm{~mm}$ \\
\hline
\end{tabular}

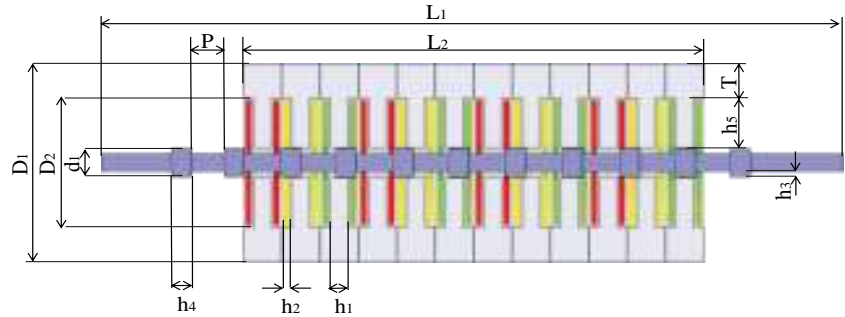

Fig. 2.Side view of schematic diagram of proposed tubular linear switched reluctance actuator.

\section{ELECTROMAGNETIC CHARACTERISTICS}

The proposed T-LSRA is analyzed using commercial 2-D finite element analysis program (Maxwell 2-D from ANSYS Inc.). 2-D FEA analysis is used since it provides lower computation power and time compared to 3-D FEA analysis. Fig. 3 illustrates the 2-D FE model. The model is an axial symmetric (RZ) model which represents a cross-section that is revolved $360^{\circ}$ around an axis of symmetry (z-axis).

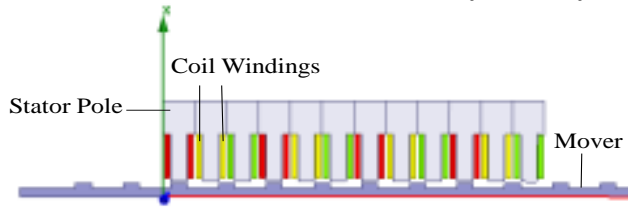

Fig. 3.2-D axial symmetric finite element model of tubular linear switched reluctance actuator.

Flux and magnetic field distribution for the unaligned, half aligned and aligned positions are shown in Fig. 4, Fig. 5 and Fig. 6 respectively. The analysis has been carried out between three positions $x=0 \mathrm{~mm}, \mathrm{x}=2.5 \mathrm{~mm}$ and $\mathrm{x}=5 \mathrm{~mm}$ which is the distance between the aligned and unaligned positions. In the analysis, the phase coil $\mathrm{C}$ is fed by a current of $5 \mathrm{~A}$. The unaligned position corresponds to the mover teeth unaligned with stators. The air gap between stator and mover teeth is higher and flux linkage is lower in this position. The maximum flux density is approximately $1.3 \mathrm{~T}$ at the mover as in Fig. 4.

At intermediate position, the magnetic field distribution shows an expansion notably along the mover. Besides, a slight increase of flux density noted on overlapping regions approximately $0.5 \mathrm{~T}$. In Fig. 6, it shows that the moving teeth are aligned with the slots of stator. The flux linkage shows large increment as the flux line canals from stators onto the mover teeth in this position.

To evaluate the magnetic characteristics, the mover of $\mathrm{T}$ LSRA is shifted from an unaligned position to a aligned position for multiple excitations current, starting from $0 \mathrm{~A}$ to $5 \mathrm{~A}$ with the steps of $0.5 \mathrm{~A}$. Fig. 7 indicates flux linkage curves of phase A for various excitations current with the position from unaligned to aligned position with the increment of $0.2 \mathrm{~mm}$. The flux linkage increases gradually for each position with different current values. Approximately around 2A, nonlinear effect of the saturation begins. 

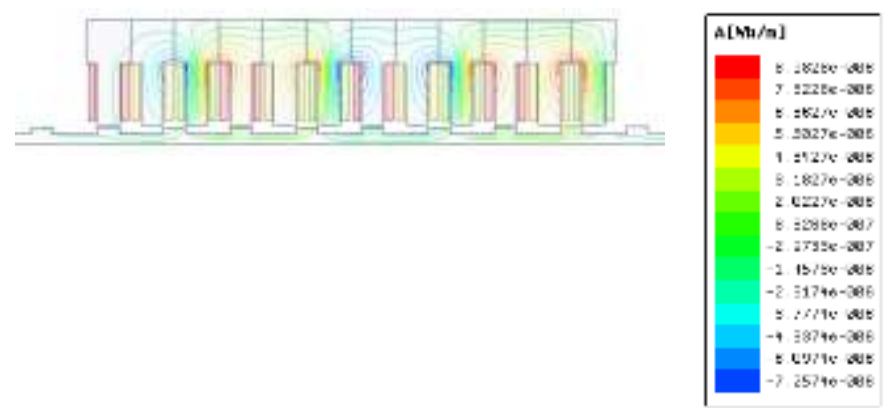

(a)

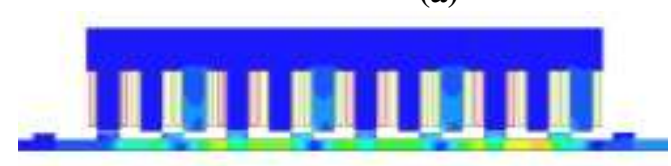

(b)

Fig. 4.Unaligned position plots from 2-D FEA (a) Flux linkage distribution (b) Magnetic field distribution.
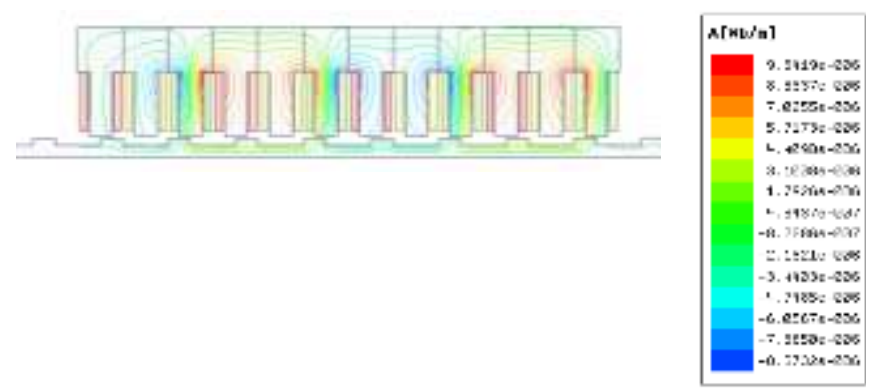

(a)

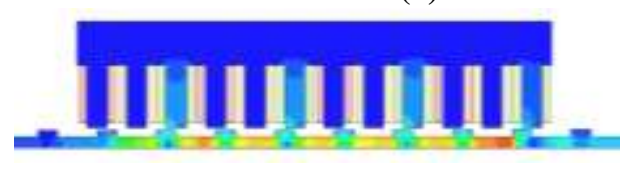

(b)

Fig. 5.Half aligned position plots from 2-D FEA (a) Flux linkage distribution (b) Magnetic field distribution.
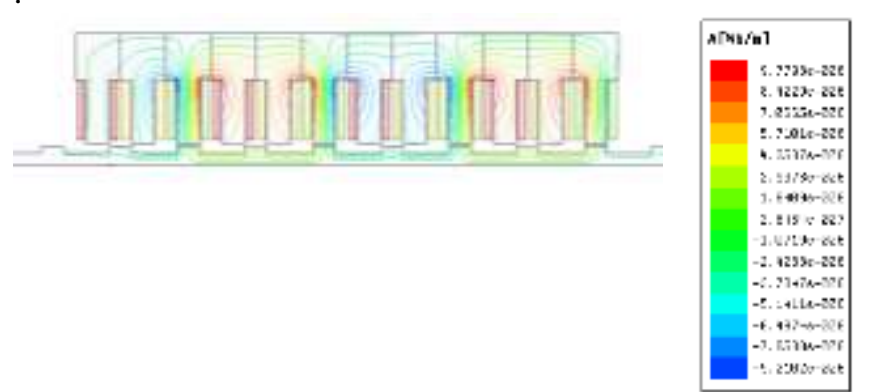

(a)
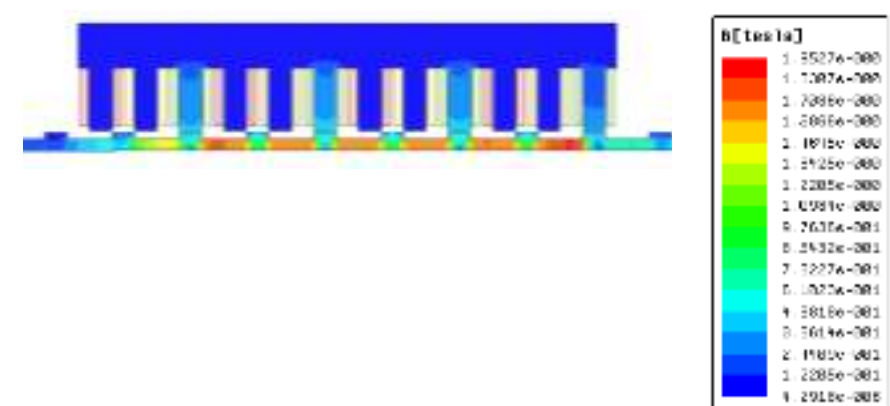

(b)

Fig. 6.Aligned position plots from 2-D FEA (a) Flux linkage distribution (b) Magnetic field distribution.

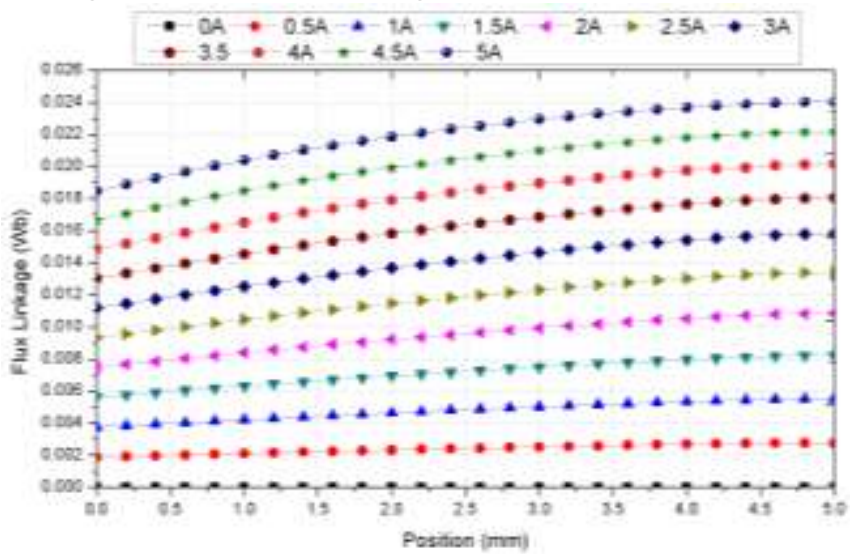

Fig. 7.Flux linkage curves of phase A.

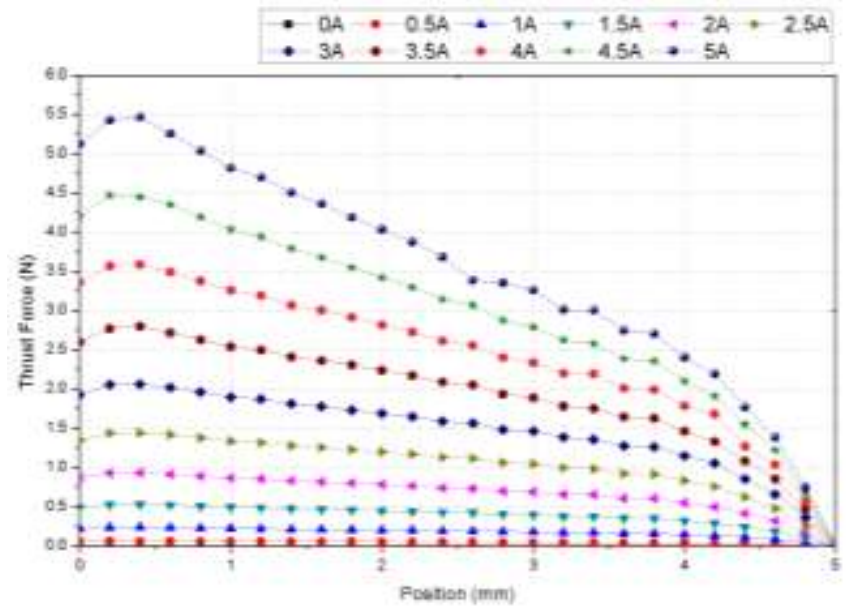

Fig. 8.Current-force-position curve.

Besides examined the magnetic characteristic of the actuator, the performance of the proposed T-LSRA is determined by the force characteristics verses the mover position and applied current. The magnetic field is evenly distributed along circumferential direction for tubular type of LSRA. Therefore, only thrust force $F_{z}$ provides significant roles in tubular type of LSRA. Fig. 8 presents the thrust force curve in relation to the position of moving teeth. For each excitation current, the maximum value of the thrust force is at $0.2 \mathrm{~mm}$ which approximately around unaligned position. When obtaining equilibrium position which the aligned position, the thrust force is almost zero. The curve represents the highly nonlinearity of the force characteristics of T-LSRA. 
Fig. 9 shows the force generated by the 3 phases of TLSRA for the same applied current (3A). The phases develop a maximum force of $2.1 \mathrm{~N}$ and the minimum force of $0.36 \mathrm{~N}$. The average force value for each phase is about $1.55 \mathrm{~N}$.

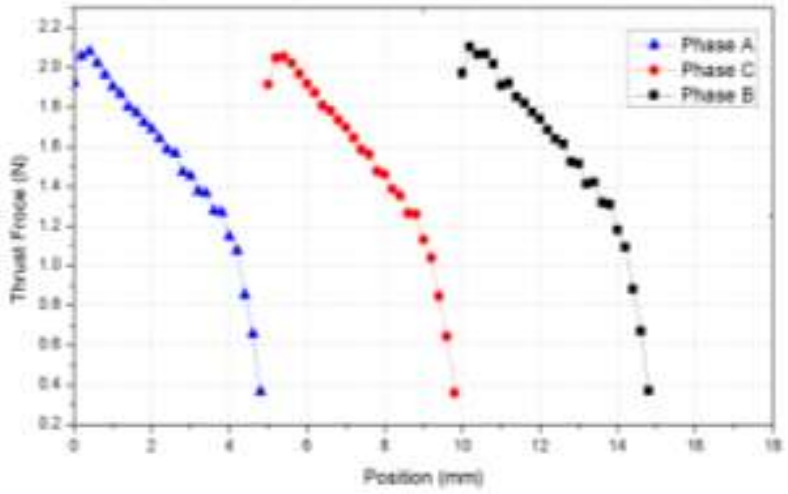

Fig. 9.Thrust force of 3 phases with $3 A$ excitation current.

\section{DYNAMIC MATHEMATICAL MODEL}

The nonlinear electrical phase equation causes the modelling of the T-LSRA is characterized with high difficulties. The designed model must take into account the nonlinearity of the force characteristics presented in Fig. 8 and the variation of the flux linkage of T-LSRA as in Fig. 7. The mathematical model can be represented by two sections, which are the electrical and mechanical model. The electrical parameters are involving the resistance (R), increment of the inductance $\left(L_{j}\right)$ which is the derivation of flux linkage $\left(\psi_{j}\right)$ and applied voltage $\left(\mathrm{u}_{\mathrm{j}}\right)$. The mechanical is including the electromechanical force $\left(\mathrm{F}_{\mathrm{x}}\right)$, mechanical load $\left(F_{L}\right)$, friction $\left(F_{0}\right)$, friction coefficient $(B)$, mover mass $(m)$, velocity (v) and position (x).

The equivalent circuit of each phase is expressed in (1) with the voltage $U_{j}$ (while $j$ is for respective phase $A$, B or C) is equal to the total of resistive voltage drop and variation of flux linkage. The expression of flux depends on the excitation current and the mover teeth.

$$
\begin{aligned}
& U_{j}=R_{j} i_{j}+d \psi_{j} / d t \\
& U_{j}=R_{j} i_{j}+\left(d \psi_{j} / d x\right)(d x / d t)+\left(d \psi_{j} / \partial i_{j}\right)\left(\partial i_{j} / d t\right)
\end{aligned}
$$

The current rate can be expressed by

$$
\left.\left.\partial \mathrm{i}_{\mathrm{j}} / \mathrm{dt}=1 /\left(\mathrm{d} \psi_{\mathrm{j}} / \partial \mathrm{i}_{\mathrm{j}}\right)\right) \mathrm{U}_{\mathrm{j}}-\mathrm{R}_{\mathrm{j}} \mathrm{i}_{\mathrm{j}}-\left(\mathrm{d} \psi_{\mathrm{j}} / \mathrm{dx}\right)(\mathrm{dx} / \mathrm{dt})\right]
$$

In (2) represents the flux characteristic for every phase in various current and the mover position. For the mechanical side, the electromagnetic force is equal to the sum of applied mechanical load, friction and inertial force as shown in (3) and the elaboration of the mechanical mathematical model is derived in (4) with $d x / d t$ is the velocity of the mover, B is the friction coefficient and $d x^{2} / d t^{2}$ is the acceleration of the motion.

$$
\begin{aligned}
& F_{x}=m(d v / d t)+F_{0}+F_{L} \\
& m\left(d^{2} x / d t^{2}\right)=F_{x}\left(x, i_{j}\right)-B(d x / d t)-F_{0} \operatorname{sign}(d x / d t)-F_{L}
\end{aligned}
$$

Finally, using (2) and (4), the model is described by the following equation:

$$
\begin{aligned}
& \partial \mathrm{i}_{\mathrm{A}} / \mathrm{dt}=1 /\left(\mathrm{d} \psi_{\mathrm{A}} / \partial \mathrm{i}_{\mathrm{A}}\right)\left[\mathrm{U}_{\mathrm{A}}-\mathrm{R}_{\mathrm{A}} \mathrm{i}_{\mathrm{A}}-\left(\mathrm{d} \psi_{\mathrm{A}} / \mathrm{dx}\right)(\mathrm{dx} / \mathrm{dt})\right](5) \\
& \partial \mathrm{i}_{\mathrm{B}} / \mathrm{dt}=1 /\left(\mathrm{d} \psi_{\mathrm{B}} / \partial \mathrm{i}_{\mathrm{B}}\right)\left[\mathrm{U}_{\mathrm{B}}-\mathrm{R}_{\mathrm{B}} \mathrm{i}_{\mathrm{B}}-\left(\mathrm{d} \psi_{\mathrm{B}} / \mathrm{dx}\right)(\mathrm{dx} / \mathrm{dt})\right] \\
& \partial \mathrm{i}_{\mathrm{C}} / \mathrm{dt}=1 /\left(\mathrm{d} \psi_{\mathrm{C}} / \partial \mathrm{i}_{\mathrm{C}}\right)\left[\mathrm{U}_{\mathrm{C}}-\mathrm{R}_{\mathrm{C}} \mathrm{i}-\left(\mathrm{d} \psi_{\mathrm{C}} / \mathrm{dx}\right)(\mathrm{dx} / \mathrm{dt})\right] \\
& \mathrm{m}\left(\mathrm{d}^{2} \mathrm{x} / \mathrm{dt}^{2}\right)=\mathrm{F}_{\mathrm{x}}\left(\mathrm{x}, \mathrm{i}_{\mathrm{j}}\right)-\mathrm{B}(\mathrm{dx} / \mathrm{dt})-\mathrm{F}_{0} \operatorname{sign}(\mathrm{dx} / \mathrm{dt})-\mathrm{F}_{\mathrm{L}}
\end{aligned}
$$

\section{RESULTS AND DISCUSSION}

The modelling of the T-LSRA was done by using MATLAB/Simulink and derivation in (2) and (4) were taken into account for the modelling design. In order to obtain the average values of the flux linkage and electromagnetic thrust force, lookup tables are used. The tables are based on the spline interpolation which the data is obtained from the Fig. 7 and Fig. 8. By using (2), the current value of each phase can be obtained for each value of flux and the mover position. The current value can be used in (4) to get the force that generated by the actuator. The simulation block diagram of the proposed T-LSRA is illustrated in Fig. 10Fig. 12.
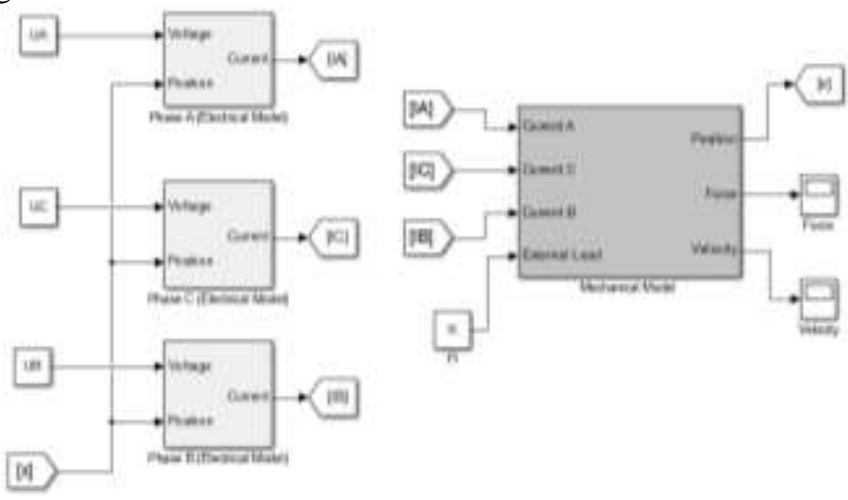

Fig. 10.Tubular linear switched reluctance simulation model.

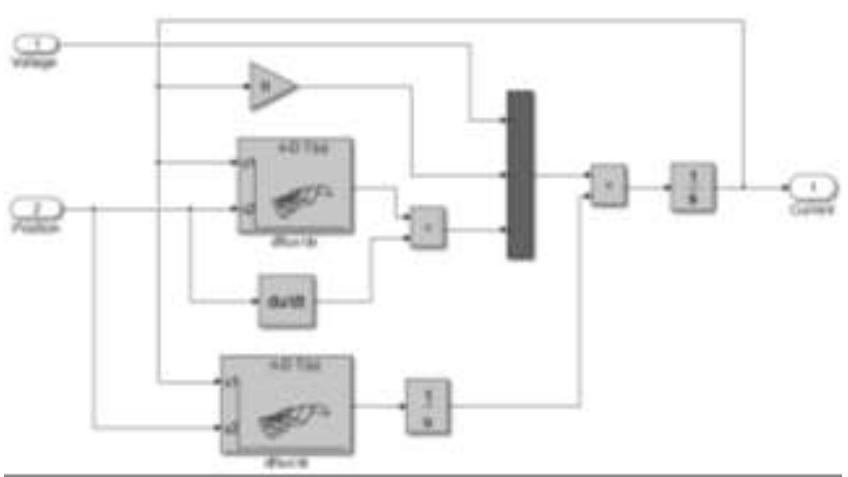

Fig. 11.Electrical model of tubular linear switched reluctance actuator for each phase. 


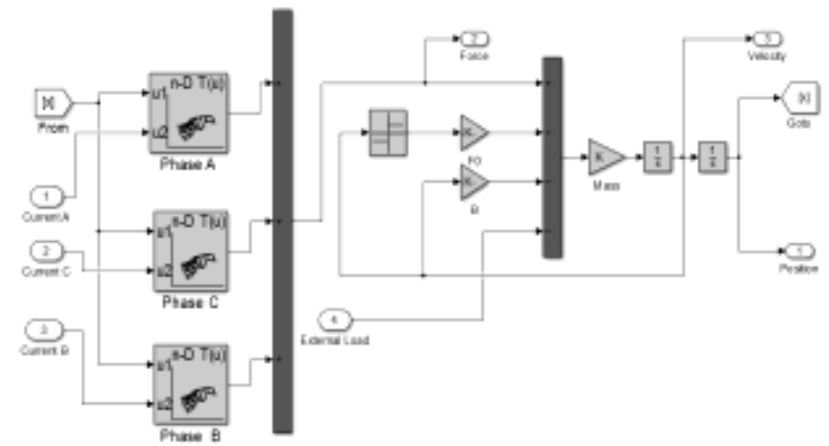

Fig. 12.Three phases mechanical model of tubular

For realizing the control technique of the T-LSRA, the verification of the T-LSRA operation is implemented. The simulation results shown in Fig. 13 show the operation in 3 phase sequential steps without external load.

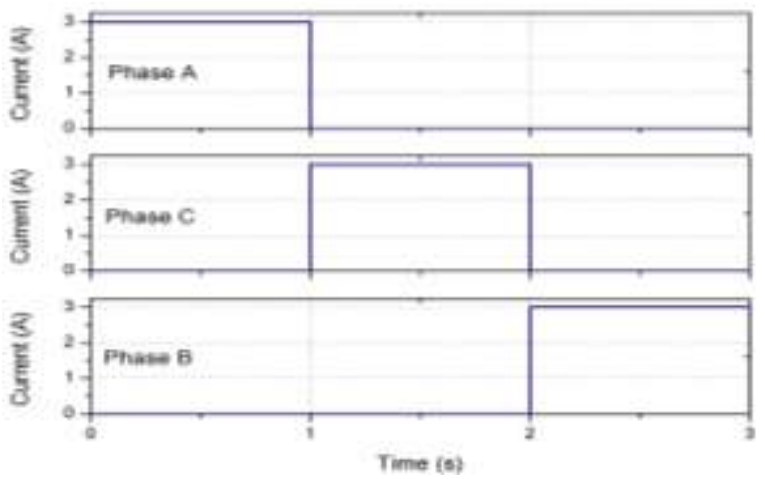

(a)

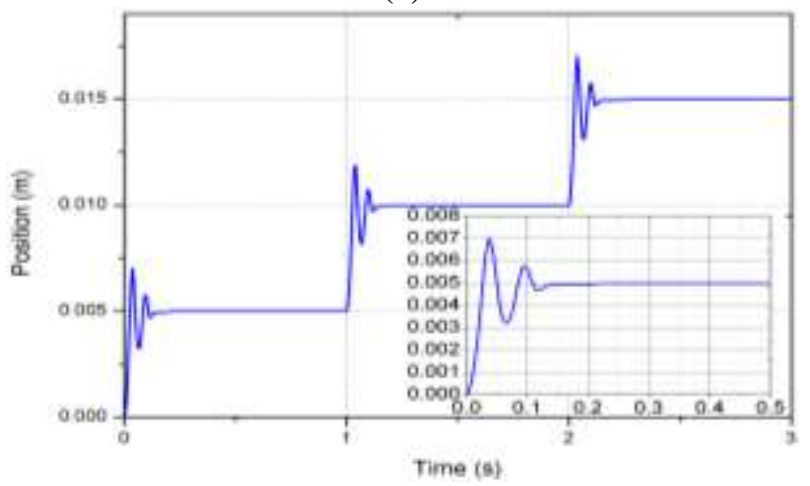

(b)

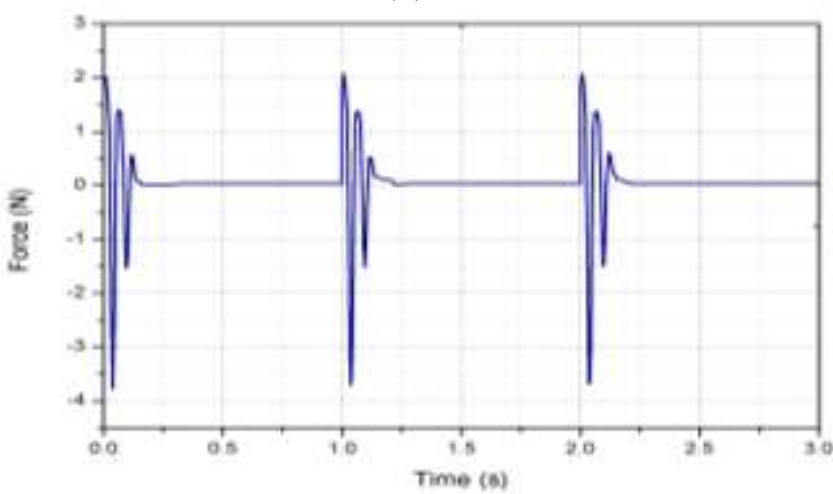

(c)

Fig. 13.T-LSRA function evaluation (a) Current excitation sequence (b) Position response in 3 phases of current excitation (c) Force responses in 3 phases of current excitation. linear switched reluctance actuator.

The current excitation sequence of the T-LSRA is starting from phase $\mathrm{A}$ followed by phase $\mathrm{C}$ and phase $\mathrm{B}$ with the amplitude of $3 \mathrm{~A}$ and the period of $1 \mathrm{~s}$ as shown in Fig. 13 (a). The presented results in Fig. 13 (b) show the mover moves to equilibrium position corresponding to $5 \mathrm{~mm}$ when the coil at phase A excited. For the next equilibrium positions which are $10 \mathrm{~mm}$ and $15 \mathrm{~mm}$, phase $\mathrm{C}$ and $\mathrm{B}$ are excited successively. According to the results, the oscillation occurs at the beginning of movement with high overshoot before reaching the equilibrium position with $0.2 \mathrm{~s}$ settling time. The force curve of the movement, shown in Fig. 13(c) indicates highly unstable operation of the proposed T-LSRA due to nonlinear characteristics of the actuator.

\section{CONCLUSION}

In this paper, modelling and simulation of proposed $\mathrm{T}$ LSRA by using FEA and MATLAB/Simulink had been carried out. Finite element analysis is essential in determining the magnetic characteristics. The obtained data from FEA is used for testing and verifying the T-LSRA operation performance and behaviour. According to the analysis, when a step current signal of $3 \mathrm{~A}$ was applied to the actuator, oscillation occurred at beginning of the motion with maximum overshooting of $2 \mathrm{~mm}$ and settling time of $0.15 \mathrm{~s}$. Besides, the force analysis showed there was nonlinear force behaviour between $-3.5 \mathrm{~N}$ and $2 \mathrm{~N}$ observed from the actuator motion. As a conclusion, the nonlinearity characteristics affect the performance of the machine. The determination of the actuator characteristics and performance is crucial for the proposed T-LSRA to realize a precision positioning system. These are planned for future work.

\section{ACKNOWLEDGMENT}

The authors would like to convey their appreciation to Motion Control Research Laboratory (MCon Lab), Center for Robotics and Industrial Automation (CeRIA) and Universiti Teknikal Malaysia Melaka (UTeM) for supporting the research and publication. Ministry of Higher Education Malaysia (MOHE) supports this research and its publication under the Fundamental Research Grant Scheme (FRGS) grant no. FRGS/2018/FKE-CERIA/F00353.

\section{REFERENCES}

1. K. B. Saad and A. Mbarek, "Half step position sensorless control of a linear switched reluctance motor based on back EMF," Autom. - J. Control. Meas. Electron. Comput. Commun., 57(3), 2016, pp. 660-671.

2. G. El-Saady, E. N. A. Ibrahim, and M. Abuelhamd, "Hybrid PD-fuzzy position controller for linear switched reluctance motor with online fuzzy logic gain scheduling of PD," 19th Int. Middle-East Power Syst. Conf., 2018 pp. 830-838.

3. J. F. Pan, W. Wang, E. Cheung, N. Cheung, X. Wu, and B. Zhang, "Self-tuning position control for the linear long-stroke, compound switched reluctance conveyance machine,” Int. J. Precis. Eng. Manuf., 19(3), 2018, pp. 387-394. 
4. L. Qiu, Y. Shi, J. Pan, and B. Zhang, "Robust cooperative positioning control of composite nested linear switched reluctance machines with networkinduced time delays," IEEE Trans. Ind. Electron., 65(9), 2018, pp. 7447-7457.

5. M. N. Maslan, K. Sato, and T. Shinshi, "Position measurement and control of a thin and compact linear switched reluctance motor with a disposable-film mover," Sensors Actuators, A Phys., 285, 2019, pp. 8088.

6. J. F. Pan, F. J. Meng, W. L. Jiang, and N. C. Cheung, "Fuzzy PID control for the linear switched reluctance machine," 5th Int. Conf. Power Electron. Syst. Appl., 2013, pp. 1-4.

7. I. Saidi, M. A. Hamdi, and D. Soudani, "Design and control of a linear switched reluctance actuator of motorization a left ventricular assist device," Biomedical Research, 29(11), 2018, pp. 2327-2336.

8. J. Garcia, P. Andrada, and B. Blanque, "Assessment of linear switched reluctance motor's design parameters for optimal performance," J. Electr. Power Components Syst., 43(7), 2015, pp. 810-819.

9. J. G. Amorós, B. B. Molina, and P. Andrada, "Modelling and simulation of a linear switched reluctance force actuator," IET Electr. Power Appl., 7(5), 2013, pp. 350359.

10. E. M. Barhoumi, M. Hajji, and B. B. Salah, "Design of a double-stator linear switched reluctance motor for shunting railway," Turkish Journal of Electrical Engineering and Computer Sciences, 22(2), 2014, pp. 302-314.

11. J. G. Amorós, B. B. Molina, and P. A. Gascón, "Simulation of linear switched reluctance motor drives," 14th Eur. Conf. Power Electron. Appl., 2011, pp. 1-9.

12. K. Sato, "Novel compact linear switched reluctance motor with a thin shape and a simple and easily replaceable mover," J. Adv. Mech. Des. Syst. Manuf., 7(3), 2013, pp. 295-304.

13. L. Yan, W. Li, Z. Jiao, and I. M. Chen, "Novel tubular switched reluctance motor with double excitation windings: Design, modeling, and experiments," Rev. Sci. Instrum., 86(12), 2015, pp. 1-12.

14. X. Xue, K. W. E. Cheng, and Z. Zhang, "Model, analysis, and application of tubular linear switched reluctance actuator for linear compressors," IEEE Trans. Ind. Electron., 65(12), 2018, pp. 9863-9872.

15. C. K. Yeo, M. M. Ghazaly, S. H. Jamaludin, and I. W. Chong, "Design optimization of a three phase tubular linear switched reluctance actuator," ARPN J. Eng. Appl. Sci., 13(5), 2018, pp. 1600-1607

\section{AUTHORS PROFILE}

Mariam Md Ghazaly is currently an Associate Professor at the Department of Mechatronic Engineering, Faculty of Electrical Engineering, Universiti Teknikal Malaysia Melaka (UTeM), Malaysia. She received her B. Eng. \& M. Eng. in the field of Electrical \& Mechatronic Engineering from Universiti Teknologi Malaysia, Malaysia in 2003 \& 2005. In 2009 \& 2012, she received her M. Eng. \& Doctor of Eng. from Tokyo Institute of Technology, Japan in the field of Mechano-Micro Engineering (Precision Engineering). Her research interest is in the field of Actuator Design, MEMS, Precision Engineering \& Non-linear Control. 